\title{
O universo dos trabalhadores dos castanhais: Cotidiano e exploração no Vale do Tocantins (1890-1940)
}

\section{Olivia Macedo Miranda Cormineiro* Euclides Antunes de Medeiros**}

Resumo: Os sertanejos pobres que viveram e trabalharam no Vale do rio Tocantins entre as décadas de 1890 e 1940 pertencem a uma categoria de trabalhadores que, não tendo sua experiência social construída na esfera da luta organizada, foram, até recentemente, despojados de historicização. Neste artigo, nosso objetivo é reconstruir algumas das dimensões da cultura de trabalho dos apanhadores de castanha-do-pará que viveram, entre as décadas de 1890 e 1940, no vale do rio Tocantins, e cujas práticas de trabalhar estão no centro de seus modos de viver e, consequentemente, constituem o nexo entre cultura e exploração, resistência e adequação cotidiana.

Palavras-chave: Trabalhadores; cultura; exploração.

Abstract: The poor backwoodsmen who lived and worked in the valley of the Tocantins River between 1890 and 1940 belong to a category of workers who, having built their social experience in the sphere of organized struggle were, until recently dispossessed of historicization. In this article our objective is to reconstruct some of the dimensions of the work culture of Brazil nut gatherers who lived between the 1890 s and 1940s, the valley of the Tocantins River, and whose work practices are central to their way of living and thus constitute the link between culture and exploitation, strength and fitness everyday.

Keywords: Workers; culture; exploration.

\section{Introdução}

Desde a década de 1970, a historiografia do Trabalho e das relações de trabalho tem ampliado suas abordagens ao voltar seu olhar, principalmente, para a cultura dos trabalhadores, seu cotidiano e suas práticas. Essa renovação significou um avanço, sobretudo, nos estudos que investigam as práticas de resistência e de negociação dos sujeitos que não se adaptam aos modelos tradicionais de lutas de

* Professora assistente da Universidade Federal do Tocantins.

** Professor adjunto da Universidade Federal do Tocantins. 
classes. Realizando uma reflexão sobre as relações entre a tradição e a inovação nas pesquisas relativas ao trabalho, o historiador social Marcel Van der Linden explica haver um consenso de que no campo da tradição, ou seja, no campo da "VeIha História do Trabalho", situa-se

[...] uma História do Trabalho [que] era institucional, focada na descrição organizacional de desenvolvimentos, debates políticos, líderes e greves. Era representada por Sidney e Beatrice Webb, a Escola Wisconsin de John Commons, dentre outros, mas também por marxistas como Philip Foner.'

Desviando-se dessa visão tradicional, cujo exemplo nos apresentou Van der Linden, surge um campo historiográfico que se volta para a reconstrução das práticas e das experiências dos trabalhadores. Os trabalhos de Christopher Hill, sendo o mais conhecido no Brasil "O Mundo de Ponta-Cabeça" e sua atuação como presidente da revista "Past \& Present" aglutinaram em torno de si estudiosos que discutiam o lugar e a importância de elementos "não econômicos" na vida social. Teóricos como Raymond Williams e historiadores como Edward Palmer Thompson, Eric Hobsbawm e Rodney Hilton desenvolveram estudos sobre a produção, a interpretação, a recepção e a ressignificação de práticas culturais concernentes aos mundos do trabalho e dos trabalhadores. A contribuição desses marxistas, atualmente reconhecidos como praticantes da "história social inglesa", reverberou positivamente na historiografia brasileira que, principalmente a partir da década de 1980, deu um salto quantitativo e qualitativo nessa mesma senda.

Com efeito, a partir dessa década, a historiografia brasileira do trabalho envida esforços para incorporar outros trabalhadores, sobretudo aqueles que vivem à margem da luta organizada, e valorizar suas práticas de subsistência e seus valores culturais como elementos importantes de sua constituição como trabalhadores. Diversos foram os trabalhos que contribuíram para esse avanço, discutindo por meio de abordagens inovadoras o trabalho e os trabalhadores: desde um tratamento diferenciado à própria noção de trabalhador, como é o caso de Silvia H. Lara3, ao incluir os escravos na categoria trabalhadores, até pesquisas voltadas para o trabalho feminino e para a mulher, que passou a ser vista também enquanto trabalhadora e não apenas como pertencente a um "gênero", caso do trabalho de Alice R. P. Abreu. ${ }^{4}$

Igualmente, historiadores (as) como José Carlos Barreiro, Luiz Felipe de Alencastro, Antonio Luigi Negro, Frederico de Castro Neves, Deá Ribeiro Fenelon e Maria Antonieta Antonacci contribuíram significativamente, não só com a reconstrução de processos por esse olhar inovador, mas também para a consolidação dessa perspectiva em termos teóricos e metodológicos. E é nessa perspectiva que estamos tratando aqui do universo dos trabalhadores dos castanhais, pois os sertanejos pobres que viveram e trabalharam no Vale do rio Tocantins entre $1890 \mathrm{e}$ 1940 pertencem a uma categoria de trabalhadores que, não tendo sua experiência social construída na esfera da luta organizada, foram, até recentemente, despojados de historicização.

1 LINDEN, Marcel Van der. História do Trabalho: o novo, o velho e o global. Revista Mundos do Trabalho, v.1, n. 1, jan.-jun. 2009, p. 12.

2 HILL, Christopher. O Mundo de Ponta-Cabeça: ideias radicais durante a Revolução Inglesa de 1640. Tradução e apresentação de Renato J. Ribeiro. São Paulo: Editora Schwarcz Ltda.,1987.

3 LARA, Silvia Hunold. Campos da Violência: escravos e senhores na Capitania do Rio de Janeiro, 1750-1808. Rio de Janeiro: Paz e Terra, 1988.

4 ABREU, Alice Rangel de Paiva. O Avesso da Moda: trabalho a domicílio na indústria da confecção. São Paulo: Hucitec, 1986. 
Assim, neste artigo, nosso objetivo é reconstruir algumas das dimensões da cultura de trabalho dos apanhadores de castanha-do-pará que viviam no Burgo de Itacaiúnas 5 , cujas práticas de trabalhar estão no centro de seus modos de viver e, consequentemente, constituem o nexo entre cultura e exploração, resistência e adequação. Um conceito central na problematização aqui proposta é o de cultura. Contudo, a concepção que adotamos não evoca o consenso das relações sociais; entendemo-la como uma gama de sistemas simbólicos e práticas que constituem experiências, padrões de comportamento e de controle social. No que concerne às práticas culturais, elas se constituem em

costumes que realizam algo - não são formulações abstratas dos significados nem a busca de significados, embora possam transmitir um significado. Os costumes estão claramente associados e arraigados às realidades materiais e sociais da vida e do trabalho, embora não derivem simplesmente dessas realidades, nem as reexpressem. Os costumes podem fornecer o contexto em que as pessoas talvez façam o que seria mais difícil de fazer de modo direto $[\ldots . .]^{6}$

Acompanhando a compreensão de Sider, partilhada pelo historiador inglês Edward Palmer Thompson (1988), estamos, aqui, menos preocupados com a ideia de classe do que com as lutas de classes construídas como modos de viver pelos apanhadores de castanha nos imensos pés existentes na vasta área de entorno da confluência dos rios Itacaiúnas e Tocantins, no Sudeste do estado do Pará. De fato, no decorrer da década de 1890, muitos sertanejos pobres, oriundos, sobretudo do Norte de Goiás, foram empurrados para as matas paraenses em razão das revoltas e conflitos armados travados entre e inter coronéis e oligarquias maranhenses e goianas.

Ignácio Baptista Moura, engenheiro a serviço do estado do Pará, em viagem ao Burgo de Itacaiúnas, durante o ano de 1896, para inspecionar o investimento que aquele estado havia feito no empreendimento de Coronel Carlos Leitão, um dos principais envolvidos na primeira Revolta de Boa Vista7, descreve a formação inicial daquela povoação da seguinte forma:

Daí a alguns minutos, saltávamos no Burgo de Itacaiúna e éramos recebidos pelos colonos, tendo à frente Carlos Leitão [...] - O primitivo estabelecimento, onde se asilaram durante quase um ano os foragidos das lutas sanguinolentas da Boa Vista, estava situado bem na foz do rio Itacaiúna, único afluente importante da margem esquerda do Tocantins [...]. A situação topográfica desse núcleo preenchia as boas condições para um futuroso estabelecimento [...] só havendo caso de febre entre as pessoas que vão acidentalmente colher castanhas na outra margem do rio ou em castanhais dessa mesma margem, conhecidos como pontos de infecção da moléstia. ${ }^{8}$

5 Atual cidade de Marabá, localizada na confluência do rio Itacaiúnas com o rio Tocantins, região Sudoeste do estado do Pará.

6 GERARD, Sider apud THOMPSON, Edward P. Costumes em comum: estudos sobre a cultura popular tradicional. Tradução de Rosaura Eichenberg. São Paulo: Cia das Letras, 1998, p. 22.

7 A primeira Revolta de Boa Vista foi um conflito que, iniciado no ano de 1892 na cidade de Boa Vista, extremo Norte de Goiás, envolveu: a Igreja, representada pelo Frei da Ordem Dominicana Gil Villanova; a administração goiana e o governo republicano, que chegou a enviar duas forças federais para Boa Vista; e os coronéis e oligarquias dos estados do Maranhão e de Goiás. Apesar dos períodos de trégua, essa revolta durou até o ano de 1895. Sobre essa questão ver: PALACíN, Luis G. Coronelismo no extremo norte de Goiás: o padre João e as Três Revoltas de Boa Vista. Goiânia: CEGRAF, 1990.

8 MOURA, Ignácio B. de. De Belém a São João do Araguaya: Valle do Rio Tocantins. Rio de Janeiro: H. Garnier, 1910, p. 311-12. 
No excerto acima, Moura expõe que a coleta da castanha era um trabalho incidental na região onde ficava o Burgo de Itacaiúna, ou seja, não era uma prática costumeira. No entanto, o próprio Moura, em outro momento de seu relato, afirma em contrário que
as maiores regiões produtoras dela [castanha-do-pará] no Pará são: o Baixo Amazonas e o Alto Tocantins [região do Itacaiúnas]. Em ambas as partes, as colheitas se fazem durante o inverno, e, quando aqueles dois rios enchem extraordinariamente acima do solo plantado de castanhei- ras [...]. A maior parte ou quase todos os colhedores de castanhas do Tocantins vêm do sertão do Maranhão e de Goiás, aonde voltam depois de finalizada a colheita, exceção de alguns que ficam definitivamente estabelecidos nos sítios [povoados] próximos aos castanhais; por isso se deve exclusivamente à castanheira e ao caucheiro a pouca coloniza- ção que já vai aparecendo nas margens do Alto Tocantins paraense. ${ }^{9}$

A despeito da ambiguidade na exposição de Moura, é consenso na historiografia que a região onde se formou o burgo de Itacaiúnas foi povoada em função de uma combinação de fatores: a transferência de sertanejos pobres que fugiam dos conflitos no extremo Norte de Goiás, a exportação da castanha-do-pará e do caucho, uma das bases para a fabricação da borracha, e o sistema e as condições de trabalho que obrigavam os apanhadores de castanha a "ficarem definitivamente estabelecidos" nos povoados próximos aos castanhais.

Moura não esclarece as condições que determinavam a fixação definitiva desses trabalhadores na região, sendo justamente a compreensão desses processos, assim como das formas por meio das quais eles configuraram a construção do cotidiano de resistência, negociação e adequação dos apanhadores de castanha dentro de relações de exploração, que discutiremos aqui. Nesse sentido, esclarecemos que, tomadas como práxis social, a resistência, a negociação e a adequação são dimensões inegligenciáveis do cotidiano de exploração dos apanhadores de castanha por comporem repertórios significativos de luta.

É importante destacar como a noção de resistência, na forma pensada por Stuart Hall, constitui-se em uma alternativa de análise, interpretação e explicação das relações de trabalho à medida que se distancia de uma compreensão de classe trabalhadora como um instituto organizado. Acerca da noção de resistência, Hall defende que

por "resistência" sinalizavam-se as formas de desfiliação [...] que, de certa forma, representavam as ameaças e negociações com a ordem dominante, que não poderiam ser assimiladas pelas categorias tradicionais da luta revolucionária de classes. ${ }^{10}$

A ideia de desfiliação, ou melhor, de deslocamento, permite empreender outras possibilidades de investigação acerca da formação da cultura de trabalho dos apanhadores de castanha, isso ao se propor que as relações cotidianas significam não só confrontos abertos com patrões ${ }^{11}$, mas toda uma variedade de negociações sutis por meio das quais esses sujeitos buscavam ressignificar sua cultura com o

9 Idem, Ibidem, p. 152-53.

10 HALL, Stuart. Da Diáspora: identidades e mediações culturais. Tradução de Adelaide La Guardia Resende et al. Belo Horizonte: UFMG, 2008, p. 214.

11 Os patrões recebem diversas denominações na região dos castanhais; são nomeados eventualmente de arrendatários, barraquistas ou aviadores. Aqui, preferencialmente utilizamos o termo patrão, embora em alguns momentos tenhamos recorrido a uma ou outra das variantes. 
fito de construir espaços de manutenção da vida em meio à luta social. Por outro lado, uma cultura partilhada por apanhadores de castanha e patrões, os exploradores da indústria castanheira, deve ser problematizada, considerando-se a questão das práticas como um feixe de ações, rituais e valores que se sobrepõe ou caminha paralelamente.

Por outras palavras, é necessário compreendermos que a cultura constitui uma mediação entre as tentativas de negociar melhores condições de vida, por um lado, e a inevitabilidade de uma sofrida submissão, por outro. É nesse sentido que o par negociação/resistência cede lugar à adequação, às vezes preferida como estratégia de manutenção da vida. De fato, à medida que um trabalhador se encontra na posição de "perdedor» de uma negociação, ele pesa, de um lado, o "preço» a pagar pela resistência e, de outro, se o caminho não seria "adequar-se" às imposições do "vencedor", ao menos provisoriamente, até que surja uma nova oportunidade de negociar.

\section{Mundo de água e de exploração: 0 discurso hegemônico acerca dos apanhadores de castanha.}

A Bertholletia excelsa, denominação científica da castanheira, aparece na região do rio Tocantins, já nas proximidades de sua confluência com o Araguaia, em sua forma mais densa: imensas florestas que comportam árvores com altura média entre 25 e 40 metros. Os frutos dessas árvores têm a forma arredondada do coco: ouriços que, recobertos de um maciço lenho, possuem no seu interior de doze a dezesseis sementes, as castanhas, que também são revestidas por uma casca lenhosa. A produção da castanha antecede a década de 1890, mas é a partir desse período que sua exportação alcança importância na economia do estado do Pará e, especialmente, na da região do Tocantins: fronteira entre Maranhão e Goiás. A constituição de um mercado europeu, no qual a demanda pela castanha cresceu vertiginosamente na década de 1910, foi determinante para a definição do tipo de exploração comercial e também das (co) formações das relações de trabaIho praticadas no interior dos castanhais.

Nesta década, a baixa comercial do látex se anunciava, mas substituindo-lhe surgia o febril comércio da castanha, que podia, conforme Josias de Almeida, ser divisado "nos batelões que acorriam de todos os pontos espalhados pelas florestas" em direção ao entreposto de Marabá. ${ }^{12}$ Nos anos que se seguiram a 1914, Marabá, antigo Burgo de Itacaiúnas, estabelece-se como o centro econômico do Pará, representando, nas palavras de Umberto Peregrino,

[...] um dos fenômenos mais curiosos da geografia econômica do Brasil. Funciona como entreposto da castanha que sustenta o Pará desde o desastre da borracha. Já foi engolida por uma enchente, em 1926. A explicação é que a cidade deve dominar as duas vias de escoamento da castanha, [pois] o fornecedor precisa estar em boas condições para fiscalizar os carregamentos que vão surgindo dos castanhais..$^{3}$

Fiscalizar os carregamentos que eram levados do interior das matas para os pequenos portos localizados às margens do Itacaiúnas e depois transferidos para

12 ALMEIDA, Josias de. Do Araguaya às Índias Inglezas. São Paulo: Nacional, 1935, p. 66.

13 PEREGRINO, Umberto. Imagens do Tocantins e da Amazônia. Rio de Janeiro: Americana, 1942, p. 27. 
o rio Tocantins, de onde seguiam para Belém, é o argumento padrão, na maioria dos relatos, para justificar a localização da cidade de Marabá. Articulada a esse argumento, surge comumente outra razão: o fato de que a cidade fora "armada na confluência do Itacaiúna, por ser local de fácil embarque [da castanha] que, pelo alto valor, era muito procurada". ${ }^{14}$

Mas a prática da fiscalização, que expõe a importância da localização de Marabá como uma escolha estratégica daquela indústria, vinculava-se, sobremaneira, a outra dimensão das relações construídas no interior dos castanhais: o sistema de aviamento. Esse sistema consistia no costume do patrão — também conhecido como barraquista ou aviador - de fornecer aos trabalhadores as ferramentas, a alimentação, os remédios e os demais utensílios que seriam usados e consumidos durante os quatro/cinco meses que, em média, durava a colheita da castanha.

Os patrões construíam barracões nas entradas das matas e neles depositavam toda a espécie de mercadorias que seriam aviadas aos trabalhadores da castanha por preço muito superior ao real valor dos produtos. O regime nos barracões se dava da seguinte forma: tudo o que era adquirido pelo apanhador de castanha era anotado em uma caderneta, com um valor majorado pelo patrão. Desse modo, como ao apanhador era permitido obter mercadorias somente no barracão, ocorria uma inversão na relação de pagamento entre patrão e camarada ${ }^{15}$, que culminava com a escravidão por dívida e, por conseguinte, com a imobilização permanente deste último no interior da região controlada pelo primeiro.

O aviamento, conhecido na região desde o final do século XIX como sistema de barracão, consistia em uma política de exploração baseada na dominação do trabalhador. Em termos gerais, essas práticas de dominação se estabeleciam em duas dimensões: a física, amplamente utilizada até mesmo nos dias atuais na região dos vales do Araguaia-Tocantins; e a que se baseava na mobilização dos valores sertanejos com o objetivo de manipular os interesses e as necessidades dos trabalhadores nos termos dos significados que as práticas de trabalho tinham para eles próprios.

Quanto à dimensão física da dominação aplicada aos trabalhadores sertanejos, os relatos dos médicos Belisário Penna e Arthur Neiva são emblemáticos. Esses médicos, em viagem pelos sertões do Brasil no ano de 1912, descrevem como funcionava o regime do barracão:

Em toda a zona [...] existe praticamente a escravidão; o barraquista ${ }^{16}$, assim se chama o dono do pessoal [dos trabalhadores], alicia gente nas povoações ribeirinhas e a leva sob promessas de grandes salários para zona a explorar [...]; no lugar onde se instalam os barracões, funda-se um armazém de propriedade do barraquista e onde o pessoal é obrigado a se fornecer pelos preços impostos pelo proprietário e que são pelo menos o dobro do corrente no "comércio" mais próximo; ao cabo de algum tempo, o empregado é devedor e está impossibilitado de sair [...]. É inútil qualquer fuga ou rebelião, as turmas são guardadas à vista por capatazes armados e o sistema é $[\ldots .$.$] generalizado [\ldots] .^{17}$

14 RODRIGUES, Lysias Augusto. Roteiro do Tocantins. Rio de Janeiro: Nacional, 1935, p. 193.

15 Camarada, segundo Ana Lúcia da Silva, era qualquer trabalhador que fizesse um ajuste de trabalho com outrem para prestação de serviços na lavoura, pecuária, empreitadas de viagens, extrativismos e serviços domésticos. Ou seja, em termos gerais, o apanhador de castanha era também um camarada, conforme o costume e a linguagem regional. Cf.: SILVA, Ana Lúcia. A Revolução de 30 em Goiás. Goiânia: Cânone, 2001.

16 Grifo do autor.

17 NEIVA, Arthur; PENNA Belisário. Viagem Científica: pelo norte da Bahia, sudoeste de Pernambuco e de norte a sul de Goiás. Coleção Memória Brasileira. v. 17. 2. ed. Brasília: CEGRAF, 1999, p. 180. 
A dominação física era, nesse sentido, parte das estratégias de exploração da mão de obra dos sertanejos, constituindo, nessa época, determinada continuidade com as práticas de escravidão ainda presentes na região. Sobretudo essas práticas de controle físico eram uma característica marcante da cultura de trabalho que desde o final do século XIX se instalava predominantemente nas relações sociais entre homens livres nos vales dos rios Araguaia e Tocantins. Entretanto, trabalhos como o da cientista social Marília Ferreira Emmi ${ }^{18}$ propõem uma abordagem diferenciada, ao apontar que dentro dos castanhais a escravização era apenas um dos campos de luta que configuram a dominação.

Ao estudar a estrutura de exploração dos castanhais no Pará entre a última década do século XIX e a década de 1960, Emmi observa existirem diversas formas de controle utilizadas por barraquistas e patrões, formas essas que eram sustentadas pelo "sistema de dívida e pela força organizada de jagunços e pistoleiros", mas também eram constituídas pelo exercício do monopólio que ia desde a apropriação da terra até o "monopólio do crédito, do transporte e, aos poucos, sobre o controle dos castanhais". ${ }^{19}$ Dentro dessa multiplicidade de formas de exploração surge, na mesma medida, uma variedade de modos de luta, que variam entre práticas de resistências e de negociações e que evidenciam a construção de uma cultura na interface das práticas de escravização, consistindo, igualmente, em um processo histórico particular.

Partindo da ideia de que essa região foi constituída de forma singular, compreendemos que a razão para que a cidade de Marabá, apesar das enchentes, se mantivesse firme no mesmo lugar pode ser problematizada a partir da indicação de Peregrino de que sua localização geográfica era definida em razão das condições propícias que a confluência dos rios Tocantins e Itacaiúnas oferecia para que o patrão/comerciante pudesse vigiar os passos do apanhador de castanha. As enchentes que assolavam a população fixa de Marabá, com efeito, não configuraram argumento suficientemente capaz de levar a cabo a transferência daquela cidade, pois a sua localização consistia em uma cerca natural: aquele mundo d'água no qual ficavam imersos os vastos castanhais favorecia o controle dos apanhadores e, muitas vezes, sua escravização a um patrão.

Empregado no Serviço da Febre Amarela, divisão do governo brasileiro em parceira com Instituto Rockfeller, o medico Júlio Paternostro é um dos poucos prepostos do estado que evidenciam, em sua narrativa, os rastros do cativeiro dos apanhadores de castanha. As condições de vida dos trabalhadores do sertão, por um lado, assombram e, por outro, seduzem esse médico que, em maio de 1935, navega o rio Tocantins por várias semanas. Seu contato com os apanhadores de castanha nos parece singular, ao menos no aspecto em que ele, diferente dos demais "narradores" com os quais dialogamos aqui, é claro, ao afirmar que a razão que impedia os apanhadores de, "durante a safra da castanha, [irem] ao povoado para comerciar" era o interesse dos "aviadores em 'isolar' na mata os apanhadores de castanha", impedindo-os de sair do castanhal. ${ }^{20}$

Mas a regulação exercida pelo patrão, a partir do ponto de localização de Marabá e dos castanhais, não se restringia ao controle da locomoção física dos apanhadores de castanha. Havia a coerção exercida pelos grupos armados, estatais

18 EMMI, Marília F. A oligarquia do Tocantins e o domínio dos castanhais. 2.ed. Belém: Gráfica e Editora Universitária da UFPA, 1999.

19 EMMI, Marília F. Os castanhais do Tocantins e a Indústria Extrativa no Pará até a década de 1960. Paper do NAEA 166. Belém: UFPA, out. 2002, p. 03. Ver: http://www.ufpa.br/naea/det_publicacao.php?id=78

20 PATERNOSTRO, Júlio. Viagem ao Tocantins. Col. Brasiliana. v. 248. São Paulo: Nacional, 1945, p. 80-1. 
ou particulares, que se colocavam a vigiar a movimentação dos apanhadores de castanha em função da inculcação da ideia de que toda a população da região de Marabá era constituída por "fugitivos dos sertões goianos e maranhenses", que tendo abandonado suas famílias não tinham qualquer preocupação com os "dias vindouros".

Seguindo essa trilha, muitas pessoas e/ou comissões que andaram pelos castanhais do vale tocantino desde o final do século XIX registraram em seus diários que a população adventícia de Marabá ou do antigo Itacaiúnas era formada, além dos patrões da castanha, por trabalhadores sem lei ou costumes. Um exemplo dessa concepção pode ser encontrado na narrativa produzida pelo aviador Rodrigues, referindo-se, no ano de 1931, às suas impressões acerca da população de Marabá:

\begin{abstract}
Estes [os apanhadores de castanha] naturalmente não traziam as famílias nessa empreitada doida de meter-se no Inferno Verde. [...] Descrever a vida de um "Castanheiro" (tirador de castanhas) é descrever os sete círculos do Inferno de Dante. Pois bem, essa gente que aqui vem, "outlaws" de novo gênero [...] vive internado por longos meses [...] durante os seis meses das águas, épocas das castanhas, a população adventícia acorre $[\ldots] .^{21}$
\end{abstract}

A ideia do castanhal como um espaço onde, ao menos até a década de 1930, a legalidade estava suspensa contribuiu para que os apanhadores de castanha tivessem sido representados como foras da lei. No entanto, essas representações não eram, por si, a força dinamizadora da exploração, mas um dos elementos que, articulado a outros como a violência, a escravização e a própria constituição de valores, constituíam um conjunto de relações disputadas e confrontadas nas práticas construídas na região castanheira. Esse caráter de além-fronteira - fora da lei, fora da civilidade, fora dos valores religiosos - é construído a partir e por meio de uma visão excludente: a visão construída a partir do discurso estrangeiro de onde emanavam algumas das concepções que demarcaram o pensamento nacional acerca do universo castanheiro.

Sobre a influência da visão estrangeira para a constituição do pensamento nacional acerca dos trabalhadores dos castanhais, encontramos no engenheiro civil Américo Leonides Barbosa de Oliveira um claro representante. Em 1938, Oliveira esteve na região tocantina, a fim de elaborar um relatório acerca da viabilidade da navegação dos rios Araguaia e Tocantins para o Ministério da Viação e Obras Públicas; naquela ocasião ele se interessou pelo extrativismo da castanha, principalmente pelos aspectos relacionados à organização econômica da atividade. Defendendo a necessidade de beneficiar esse produto na própria região, e considerando a sazonalidade um problema a ser resolvido, esse engenheiro apoia essa sua compreensão na concepção do professor da Universidade de Michigan, o geógrafo norte-americano Preston Everett James, que estudou os aspectos humanos da geografia amazônica. Segundo Oliveira:

O Prof. Preston E. James, da Universidade de Michigan, estudando a geografia do Brasil impressionou-se com a frouxidão do laço que liga o homem a terra: na "Hylaea" tocantina, mais do que em qualquer região do país nota-se o divórcio completo entre o homem e a terra. O explorador investe desaparelhado de tudo e desajudado de todos. A mata o

21 RODRIGUES, Op. cit., p. 193. 
apavora. Mal termina o trabalho, volta apressado, para gozar o fim da "saison" em Marabá. Ali passa o resto do ano, inativo, sacando sobre a futura safra, ou regressa ao sertão aproveitando os últimos repiquetes. ${ }^{22}$

A ideia do explorador sazonal que retira o produto e abandona a terra é um dos aspectos levantados por Oliveira como sendo o cerne do pensamento de James acerca da ocupação do território amazônico. Na compreensão do engenheiro civil, ancorando-se em James, existe a necessidade de estabelecer uma normatização da produção extrativa que conduza à ocupação e à fixação do homem no território; contudo, na concepção de James, segundo o próprio Oliveira, a responsabilidade dessa situação é do trabalhador, "que não altera seus maus hábitos e sua frivolidade, buscando antes os ganhos fáceis e rápidos promovidos pelos patrões e pelos grandes exportadores estrangeiros". ${ }^{23}$

Com efeito, muitas das concepções acerca dos trabalhadores sertanejos, dentre eles os apanhadores de castanha, estão diretamente vinculadas às práticas de exploração que articuladas à visão de mundo estrangeira terminam por estabelecer parâmetros interpretativos que se confrontam com as experiências vividas na região. As ideias estrangeiras se movem entre práticas de exploração e de controle social, mas encontram, dentro das próprias relações, forças sociais que Ihes resistem. Contudo, sustentada nas ideias de submissão e de indolência que se alternavam nas narrativas, era a imagem de decadência que prevalecia acerca dos apanhadores de castanha.

Reflitamos sobre os acontecimentos do verão de 1896, ocasião em que Ignácio Baptista de Moura relata a sua chegada ao Vale do Tocantins. Seu olhar foi menos surpreendido pelas densas matas de castanhais do que pela imagem da decadência impressa na face do apanhador de castanha. Nas margens do Itacaiúnas, ele observa velhas casas de palha, habitadas pelos inúmeros grupos que se internavam nas florestas alagadas em busca do precioso fruto da castanheira. Essa indústria, que começava a representar a riqueza do Pará em 1896, surpreende Moura com a pobreza dos homens que ali "habitam". Contudo, para esse paraense, a responsabilidade pela indigência, pela forme, pela doença e pelo fato de ano após ano o barqueiro de Hades navegar o rio Tocantins, um dos círculos do Inferno de Dante segundo Rodrigues, em busca “daquela massa de forasteiro" era definida

pelo pouco cuidado com que [aquela] gente ia às matas — sem calçado, pisando em charcos, logo pela madrugada, bebendo água das fontes infecciosas, mal se abrigando em palhoças provisórias, contra as chuvas abundantes e alimentando-se insuficientemente. ${ }^{24}$

A despeito de como interpreta a questão da "miséria humana", aquele funcionário do estado do Pará plasma em sua retina algo que, segundo ele, é belo ver: "as margens risonhas do grande rio, pelo tempo da colheita, semeadas de sítios cheios de crianças e mulheres". ${ }^{25}$ Após descrever vividamente a decadência dos trabalhadores da castanha, torna-se difícil precisar o que Moura estaria compreendendo como belo; porém, ao demarcar em sua narrativa a presença de mulheres e crianças nas matas da castanha, mesmo não esclarecendo os moldes familiares,

22 OLIVEIRA, Américo L. B. O Vale Tocantins-Araguaia: Possibilidades Econômicas, Navegação Fluvial. Rio de Janeiro: Imprensa Nacional, 1941, p. 35-6.

23 Idem, Ibidem, p. 37-8.

24 MOURA, Op. cit., p. 153.

25 Idem, Ibidem, p. 153. 
ele aponta para um caminho diferente daquele trilhado por Rodrigues, que afirmou que os apanhadores de castanha "naturalmente não traziam as famílias nessa empreitada doida de meter-se no Inferno Verde". ${ }^{26}$

Rodrigues não chegou a afirmar que inexistiam mulheres nos castanhais, mas, para ele, a presença feminina estava restrita às prostitutas que se embrenhavam nas matas com o objetivo de "reter" o que o apanhador de castanha teria recebido durante a safra. Segundo esse piloto-aviador, "as mulheres todas são de todos, desde que haja dinheiro, [...] crian[do] uma mentalidade normal de concubinato, dada a maioria desses homens ser casados". ${ }^{27}$ No que concerne à dominação, as diferenciadas relações entre homens e mulheres descritas por Rodrigues nos leva a questionar os significados da articulação construída entre trabalho e moralidade na região dos castanhais do Vale do Tocantins-Araguaia.

A representação de Rodrigues sobre os apanhadores acerca-se de metáforas cujos sentidos construídos por esse piloto-aviador articulavam a constituição implícita de normas e valores sociais à prática ideológica de ordenamento hegemônico com vistas a desqualificar o apanhador de castanha em sua condição de trabalhador. Em sua compreensão, "não havia guias morais [fosse] de qual religião fosse" em Marabá ou na região, pois, em 1931, "ainda se v[ia] um indivíduo publicamente amasiado com a mulher do outro, vivendo os três em comum como se fosse a coisa mais natural do mundo". ${ }^{28}$ Afirmar que não houvesse famílias, organizadas nos moldes tradicionais, na região dos castanhais e que as mulheres ali presentes fossem todas prostitutas é um argumento que, em primeiro lugar, volta-se para a ideia de desordem e, por conseguinte, para a necessidade de ordenamento social. A esse respeito, Rodrigues expõe, sucinta e claramente, que essa regulação social chegaria a Marabá "so[mente] com a lei". 29

Mas a ordem/desordem sobre a qual a lei e seus agentes atuavam preferencialmente não era aquela que tratava das relações amorosas ou conjugais naquele sertão particular, embora esta última tenha servido muitas vezes de justificativa para a manutenção e a intervenção de forças policiais nos castanhais. O campo de atuação dessas forças era, a despeito da manutenção da moralidade, quase sempre "uma desculpa" para controlar os trabalhadores, o que Neiva e Penna esclarecem com primor ao narrar a ação da polícia como braço armado dos barraquistas em 1912.

A "rebelião" ou a tentativa de fuga empreendida por trabalhadores cativos de barraquistas eram punidas com violência e com força pela polícia, conforme relatam estes médicos:

as autoridades prestam mão forte [aos patrões] que procura o devedor fugido e, tivemos o desprazer de ver a prisão de 4 camaradas levados à viva força para o barracão dum barraquista, já celebrizado em toda a zona pelos crimes cometidos. ${ }^{30}$

Entretanto, mesmo na ausência das forças policiais, os patrões não hesitavam em manter sua própria milícia, principalmente porque os ataques indígenas eram uma justificativa plausível para que as turmas de castanheiros fossem "guardadas à vista por capatazes armados e o sistema [era] generalizado [...]. ${ }^{31}$

26 RODRIGUES, Op. cit., p. 193.

27 Idem, Ibidem, p. 193

28 RODRIGUES, Op. cit., p. 193-4.

29 Idem, Ibidem, p. 194

30 NEIVA; PENA, Op. cit., p. 180.

31 Idem, Ibidem, p. 180. 
É nessa perspectiva que as palavras de Oliveira surgem preenchidas de sentido: "a castanha é hoje o sustentáculo da máquina administrativa do Pará. Em torno dela giram as leis, os regulamentos, os negócios e as negociatas". ${ }^{32}$ Nós acrescentaríamos: em torno dela gira a construção sobre o apanhador de castanha que mobiliza valores e padrões morais para legitimar ações que visam regular e normatizar as práticas de trabalho no castanhal.

De certa forma, a própria presença dos prostíbulos e bares servia à prática de escravização dos trabalhadores da castanha que, como relata Rodrigues, após longos meses internados nas matas e, voltando a um "lugarejo ou cidade, ao enxergar uma mulher, branca, preta, índia, mulata, cabrocha, seja lá o que for, eles se "espalham"”. ${ }^{33}$ De fato, embora a presença de famílias fosse rechaçada ou negligenciada em parte das narrativas, a presença de mulheres livres - como eram nomeadas as prostitutas - nos povoados próximos aos castanhais é registrada desde o final do século XIX. Em 1897, Ignácio Batista de Moura observa que nas proximidades de Marabá, no lugar chamado Areião, muitos barraquistas mantinham mulheres ao seu serviço com o objetivo de

fixar permanentemente os trabalhadores da castanha, que ou se endividavam comprando produtos secos e molhados ou comprando as benesses das moças que trabalhavam para os mesmos barraquistas fornecedores dos produtos requeridos pelo trabalhador. ${ }^{34}$

Muitas dessas mulheres, agenciadas pelos patrões dos próprios apanhadores de castanha, eram o instrumento do cativeiro vivido pelos trabalhadores, pois, não conseguindo saldar seus haveres, tornavam-se presos ao barracão, não tendo, de fato, outra opção que não a de esperar outra safra vendo sua dívida crescer dia após dia. Assim como Moura, Rodrigues não parece alheio a essa espécie de cativeiro do trabalhador junto ao barracão do patrão, pois ao reproduzir a lenda do pássaro jacamim, presente no imaginário do sertanejo do Vale do Araguaia-Tocantins, representa alegoricamente a mesma relação entre trabalho e moralidade, mas dessa vez em uma imagem invertida. Estando ele ainda em Marabá, recebeu diversos presentes dos moradores da região e dentre eles se achava "um casal de jacamins, lindas aves pretas, do tamanho de uma galinha, cujo pescoço parece veludo negro $[\ldots] " . .35$

Os jacamins são aves singulares que, além da beleza ímpar, são conhecidas por sua submissão à fêmea, cuja característica principal seria a relativa facilidade com que os machos se fixam definitivamente ao local escolhido por seu par para construir o ninho. Segundo as lendas amazônicas, Yacamim era uma índia que fugira de sua tribo em busca de um casamento. Encontrada no interior da mata, foi levada até um guerreiro rebelde e inquieto que por ela se encantara. Contudo, logo após se casarem, foram tomar banho em um riacho, onde se esfregaram, por descuido, na erva jacamim ou jacamincá: vendo-se, o casal, transformados nas aves jacamins.

Transformados nas belas aves negras, o casal deixou para trás tanto a rebeldia quanto a inquietude, tornando-se, desde então, seres sedentários que, facilmente domesticados, prestavam-se à servidão do terreiro. Conforme Rodrigues,

\footnotetext{
OLIVEIRA, Op. cit., p. 36.

RODRIGUES, Op. cit., p. 193

4 MOURA, Op. cit., p. 174.

35 RODRIGUES, Op. cit., p. 199.
} 
para domesticar o jacamim era necessário ir "na época própria [...] à mata [...] trazer companheira para o quintal, que também se acostuma e fica", porém o acostumar-se e ficar das aves é traduzido por Rodrigues para a experiência humana por meio da seguinte expressão: "Quantos jacamins humanos andam por aí?! [...] Que se domesticam como cachorros". ${ }^{36}$

Transpondo essa metáfora para o cotidiano dos trabalhadores nas matas de castanhais, percebemos vestígios de que Rodrigues relaciona-a com uma das estratégias de exploração construídas pelos patrões: a utilização das "mulheres da vida" para endividar e finalmente escravizar os apanhadores, uma prática usual dentro dos castanhais e que Rodrigues, assim como Moura, deve ter tido a oportunidade de observar. Atentando ao significado dessa lenda na narrativa de Rodrigues, compreendemos que esse piloto-aviador, ao se referir aos homens que se deixavam domesticar, estaria aludindo ao caráter da dominação sofrida pelo apanhador de castanha: a regulação do trabalho exercida pelos patrões por meio da prostituição.

Contudo, somente no dia 27 de março de 1944, mais de uma década após sua passagem por Marabá, é que surgem evidências da relação construída por Rodrigues entre a "domesticação" do jacamim e a dos trabalhadores por intermédio das "fêmeas". Advogando a causa da criação de um território federal que englobasse o Norte de Goiás e o Sul do Maranhão, publica nessa data um artigo no Jornal À Tarde, editado na cidade Carolina, estado do Maranhão, apontando que a causa da pobreza e da decadência da região eram a falta de iniciativa privada, o esquecimento por parte do estado e

os frouxos laços de moralidade que, além de destruir as famílias, são artifícios da escravização dos trabalhadores nas fazendas, nas roças e nas matas de castanhais. A exploração é ajudada pela fraqueza da pudicícia que a par do desleixo experimentado pelos trabalhadores que frequentam parte do ano o baixo meretrício, se deixa domesticar como na lenda das aves negras do amazonas. ${ }^{37}$

A lenda do jacamim orienta, em Rodrigues, a construção de uma metáfora acerca das relações de trabalho nos vales dos rios Araguaia e Tocantins, mas não se trata apenas de pensá-la como uma representação vazia de significados sociais. Ao contrário, ela exemplifica relações concretas que vinculam uma "moralidade" específica às intervenções dos patrões na e para a regulação do trabalho que, de certa forma, reforçou os repertórios de exploração e de resistência cotidiana dos apanhadores de castanha no espaço próprio onde constituíram seus modos de viver. Nesse sentido, historicizar o cotidiano desses trabalhadores, como faremos a seguir, pode lançar luzes sobre os significados das narrativas acerca de seus modos de viver.

\section{Sem sol e sem luz: o cotidiano e a experiência de exploração do apanhador de castanha}

Problematizar o cotidiano dos apanhadores de castanhas nos leva por outros caminhos que não aqueles que nos querem conduzir os discursos e as práticas

36 RODRIGUES, Op. cit., p. 199.

37 RODRIGUES, Lysias A. apud ROCHA, Paulo. O sonho tocantinense nas páginas da imprensa. Brasília: Editora Singular, 1989, p. 218. 
de estrangeiros ou de alguns agentes do estado brasileiro. De fato, produzir esse deslocamento pressupõe pensar a experiência familiar do castanheiro em articulação, tanto com suas práticas de resistência e/ou adequação quanto com as manobras e estratégias de exploração e dominação mobilizadas pelos patrões.

Os relatos sobre os quais lançamos nosso olhar são, em parte, os mesmos por meio dos quais, acima, buscamos analisar as concepções de estrangeiros e nacionais que, a serviço do estado ou em missões de estudo, estiveram na região dos castanhais e registraram suas impressões e concepções sobre as práticas sociais naqueles espaços. Médicos, aviadores e barraqueiros se dedicavam a atividades variadas, contudo, tinham em comum o fato de compreenderem aquela realidade como parte de um mundo diferente daquele de onde vinham, e, por conseguinte, viam-no por um prisma diferente dos que ali construíam suas experiências de viver e trabalhar. Entretanto, esses homens construíram visões acerca do universo dos castanheiros que se contrapunham quanto aos significados informados pelas práticas de trabalho.

De um lado, havia os que propunham que a decadência nas relações de trabalho e no cotidiano, marcado pela pobreza e pela prostituição, era algo inevitável, caso do engenheiro Ignácio Baptista Moura que, observando as duras vidas dos trabalhadores da região, compreende-as como uma instância naturalizada das relações sociais no sertão. De outro lado, há os que assinalaram em suas narrativas a exploração dos trabalhadores da castanha e o quanto as relações de trabalho no sertão eram diversas das do litoral, caso do médico Júlio Paternostro, que busca dar um tom de denúncia aos seus relatos.

Perscrutaremos, enfim, o relato de memória da professora Ana Rosa Rodrigues, que constitui, de um lado, evidências e indícios da realidade vivida cotidianamente pelo trabalhador da castanha e, de outro, um espaço narrativo que disputa os significados acerca do universo dos apanhadores de castanha. No relato Lembranças de um castanheiro do Pará, publicado em 1942, encontramos vestígios de uma história silenciada, a história dos trabalhadores sertanejos que, mesmo antes de a historiografia lançar-lhe um olhar de esguelha, já era visitada pela pena dos memorialistas. Com efeito, antes dos historiadores, outros sujeitos andaram e falaram sobre as regiões centrais do país, banhadas por rios, produtoras de riquezas e principalmente regiões onde pessoas viveram, e ainda vivem, e constroem suas histórias.

Paternostro foi um desses homens que visitou o sertão. Navegando em uma embarcação gaiola ${ }^{38}$, durante o mês de maio de 1935, Paternostro descreve o cotidiano dos apanhadores de castanha de forma similar à que Moura relata ter visto em sua viagem no ano de 1896, embora os sentidos atribuídos pelo médico sejam bem mais explícitos que os do engenheiro. A esse respeito, não é improvável que o interesse pela história clínica dos sertanejos o tenha conduzido a construir uma narrativa preenchida dos costumes e das práticas cotidianas dos trabalhadores da castanha. A paisagem dos castanhais, descrita por Paternostro, era o interior das matas por onde corriam igarapés, os quais os apanhadores de castanha atravessavam a pé ou em canoas, quando mais profundos:

O trabalho consist[i]a em catar os ouriços dos vários pés e juntá-los em montes. Quebram-nos quer com um pedaço de pau, quer com um facão a que chamam "colin", e soltas as castanhas [...] recolhem-nas a um cesto chamado "panero" ou "joão maxim".39

38 Gaiola é uma embarcação a motor movida à gasolina, típica dos rios Tocantins e Amazonas, apropriada para águas de navegação franca.

39 PATERNOSTRO, Op. cit., p. 83-4. 
Panero é o nome que Júlio Paternostro utiliza para identificar o cesto que, inclusive, ainda hoje é muito utilizado para o transporte de produtos extrativos da lavoura, na região dos vales do Tocantins-Araguaia. Em média, cada cesto comportava sessenta quilos de castanha, que eram transportadas nas costas do apanhador do centro da mata até as pontas, locais onde embarcações esperavam para embarcar o produto em direção a Marabá. Dos centros das matas de castanhais até essas pontas, o percurso nunca era inferior a quinhentos metros, o que tornava o trabalho extenuante. Entretanto, cansaço sofrido pelo trabalhador castanheiro não pode ser compreendido apenas como um trabalho penoso, pois aquela experiência conduzia, para além da fadiga, à invalidez e à morte do trabalhador.

Moura também aponta a precariedade da vida dos apanhadores, quando diz que, "perseguidos pelas febres intermitentes, muitos eram dizimados anualmente"..$^{40}$ A manifestação lacônica de Moura, ao informar sobre a "dizimação" do trabalhador da castanha, talvez ocorra em razão de esse engenheiro responsabilizar o próprio trabalhador pela situação. Não obstante, do termo dizimado surgem rastros de uma carga sintagmática que vale a pena perseguir em outros relatos da mesma época ou de épocas aproximadas, isso porque podem revelar indícios da realidade do trabalhador nas regiões centrais do Brasil entre o fim do século XIX e as primeiras décadas do século XX.

Em Paternostro, esses rastros estão particularmente marcados quando ele destaca que as condições precárias da vida determinavam a doença, a invalidez e a morte do apanhador de castanha. Esse médico descreve pontualmente algumas das doenças que atacavam os trabalhadores dos castanhais, o que nos auxilia a entender as experiências que preenchem o sentido da "dizimação" cotidiana enunciada por Moura. Segundo Paternostro:

\footnotetext{
Além da malária endêmica, tive notícia de uma infecção que nos meses de maio a junho vitima os extratores de castanha. Segundo informações dum Sr. Juvêncio Alves, em 1924, esta doença matou trinta indivíduos em Joana Peres. Os sintomas descritos coincidem com os dos casos clínicos observados pelo Dr. Júlio Barcas de Marabá. Febre, vômito, escarros sanguinolentos. Parece tratar-se duma forma epidêmica de bronco-pneumonia, a que os nativos chamam catarro. ${ }^{41}$
}

Paternostro faz referência, em primeiro lugar, às mesmas "febres intermitentes" que, em 1896, Moura também havia feito. Entretanto, o médico detém-se com mais vagar a descrever as doenças do sistema respiratório, comuns entre os apanhadores, em razão das longas temporadas que eles permaneciam nas úmidas e sombrias florestas de castanheiras. Mas as razões de Paternostro, ao apresentar a sintomatologia dessas doenças, ultrapassam o interesse clínico; na verdade, essa exposição é o fechamento de uma argumentação, sutil é verdade, acerca das condições de trabalho daqueles trabalhadores. Vejamos como ele narra ser a vida do apanhador:

Durante a safra da castanha, os habitantes da mata não vão ao povoado para comerciar ou tomar parte em funções religiosas e festivas. [...] Os arrendatários e "aviadores" utilizaram-se dos meios de transportes [indo às pontas buscar a castanha ao contrário de permitir que o trabalhador vá ao povoado] para "isolar" na mata, os apanhadores de castanha $[\ldots] .{ }^{42}$

40 MOURA, Op. cit., p. 153.

41 PATERNOSTRO, Op. cit., p. 82.

42 PATERNOSTRO, Op. cit., p. 82. 
A explanação sobre as doenças e a morte daqueles trabalhadores é, conforme interpretamos, o fechamento de uma relação que Paternostro procura construir entre trabalho e doença, identificando-a com o processo de dominação cotidiana que os "párias do interior do Brasil" experimentavam sob o jugo dos patrões. De fato, para Paternostro, as doenças sofridas pelos trabalhadores sertanejos são resultado de seu cotidiano de trabalho, mas não a causa: a razão seria a exploração e a dominação experienciada por aqueles sujeitos que, vivendo isolados no castanhal, também estariam exilados de quaisquer direitos como trabalhadores.

Procurando entender a relação entre discurso médico e políticas saneadoras do sertão, Nísia Trindade Lima problematiza as conclusões de Paternostro acerca do universo sertanejo, presentes em Viagem ao Tocantins. Lima esclarece, oportunamente, que, para o médico, a ideia que prevalece é a de um sertão distante, separado geográfica e, sobretudo, culturalmente do restante do país, derivando dessa concepção a compreensão de que o progresso chegaria à região dos castanhais somente quando se voltasse para o litoral, buscando seguir a civilização. ${ }^{43}$

Concordamos com Lima no que se refere à concepção de Paternostro sobre o sertão. Contudo, há na narrativa do médico ao menos um aspecto que o diferencia da maioria das pessoas que viajaram pelo sertão e pelas regiões centrais do Brasil: ele não responsabiliza exclusivamente os trabalhadores sertanejos pela "decadência” na qual estão inseridos. Especificamente quanto aos apanhadores de castanha, Paternostro defende que as condições de vida daquelas pessoas são consequência de práticas atrasadas dos patrões, resultando disso o fato de se tornarem sujeitos enfermiços. Nesse caso, a vinculação construída entre trabalho nos castanhais e doenças vai além dos interesses profissionais do médico: trata-se de sua compreensão social acerca da experiência cotidiana dos apanhadores de castanha no hinterland.

Quando nos detemos com mais atenção no próprio vocabulário médico que Paternostro mobiliza, percebemos que em muitos momentos de sua narrativa o foco não é a ciência, mas a sociedade e, mais propriamente, uma cultura do trabaIho. A sociedade que ele vê nas regiões centrais do Brasil é traduzida para um vocabulário clínico, cujo sentido metafórico propõe expressar a compreensão daquele médico sobre os sistemas sociais de exploração. A doença que grassava na região de Marabá era, na visão de Paternostro, fruto das condições de trabalho que, conforme um relato da época sobre a vida de um castanheiro, reduzia os homens, "ainda jovens, a trapos humanos. Meu avô e meus tios morreram todos antes de completar cinquenta anos. Vítimas do castanhal: febres, flechas, frio, fome. Honrados, se deixaram vencer pela força da mata". ${ }^{44}$

O trecho acima, embora escrito com um tom nostálgico, relata a vida de um apanhador de castanha que viveu em Marabá a partir de 1914 e cujo elo com o que descreveu Paternostro se dá pela ideia de que o trabalho no castanhal aniquilava as pessoas ou, como disse Moura, dizimava, anualmente, muitas delas. Para Paternostro, contudo, a palavra doença constituía um duplo significado: de um lado era uma consequência do sistema de exploração do capitalista; de outro, a metáfora, adequada para designar a patologia social que assolava o sertão e cujo representante mais próximo eram os patrões que

43 LIMA, Nísia Trindade. Uma brasiliana médica: o Brasil Central na expedição científica de Arthur Neiva e Belisário Penna e na viagem ao Tocantins de Julio Paternostro. In: História, ciência, saúde. Manguinhos. v.16 supl.1. Rio de Janeiro. jul. 2009. Disponível em: http://www.scielo.br/scielo.php?pid=S010459702009000500011\&script=sci_arttext. Acessado em: 20/04/2012.

44 RODRIGUES, Ana Rosa. Lembranças de um castanheiro do Pará. Belém: Lusíada, 1942, p. 39. 


\begin{abstract}
alugam os sertanejos para apanharem as castanhas. Em todo o vale do Tocantins usa-se o verbo alugar em vez de empregar. Exprime com nitidez a situação em que se encontram os sertanejos, da classe dos párias de nossa civilização. Há mais de cem anos que trabalham numa pátria onde não se lhe reconhecem os direitos, invalidam-se, morrem no serviço, sem a menor assistência. Constituem um exército de doentes sociais. 45
\end{abstract}

Embora voltasse o olhar para o cotidiano de exploração do apanhador de castanha, Paternostro, interessado em encontrar no interior do país experiências produtivas cujos critérios de normalização do trabalho assegurassem alguns direitos aos trabalhadores, ao não encontrar tais condições, parece não compreender que os sertanejos que trabalhavam nos castanhais, mesmo não tendo acesso a "direitos trabalhistas", elaboravam e reelaboravam as experiências de opressão a que estavam submetidos em seu próprio "viver o trabalho". No limite de sua compreensão desses sujeitos como vítimas passivas do sistema vigente, àquele médico somente foi possível assinalar as condições miseráveis dos trabalhadores, mas há evidências de outras dimensões das experiências de trabalho dos apanhadores de castanha, principalmente no que concerne às negociações e às resistências.

\title{
Memórias ilhadas: família e escravidão nas matas do castanhal
}

Voltemo-nos para um dos poucos relatos memorialísticos acerca de um apanhador de castanha que resistiu ao tempo. Publicado no ano de 1942, Lembranças de um castanheiro do Pará é um relato no qual a professora Ana Rosa Rodrigues narra as lembranças de Braulino Rosa Rodrigues, seu pai, acerca dos "tempos que vivia no castanhal sofrendo o rigor das chuvas e o ataque das febres". ${ }^{46}$

Sobre Rosa Rodrigues não há muitas informações, além do fato de ter sido "levada de Marabá, em 1919, pela família de um sírio que comercializava naquela praça, e criada em Belém" 47 , onde teve a oportunidade de estudar, formando-se professora. Na introdução desse relato de memórias é a própria autora quem esclarece ter ido residir em Belém e somente ter retornado a Marabá “em 1935, depois das primeiras viagens de avião, onde passou a lecionar em uma escola"48, talvez a primeira do lugar.

As lembranças de Braulino Rosa são parte de uma memória familiar que ele compartilhou socialmente com os habitantes das matas de castanhais e que a autora reconstrói na interface de mundos diferentes, porém interligados. Apoiando-se na norma culta da língua, a autora inscreve em sua narrativa o rumor de uma oralidade cuja compreensão não parece ser difícil para ela. Por outro lado, o mundo do letramento que Rosa Rodrigues “conheceu” em Belém também atravessa a memória reconstruída por ela sob a forma de um discurso permeado pelas concepções e convenções da classe dominante acerca do trabalho e dos trabalhadores.

Braulino Rosa, pai da autora, nasceu no final da década de 1880 em uma fazenda na "beira do rio Itapecuru", Sul do Maranhão. "Sua mãe, d. Alfonsina, já tinha

45 PATERNOSTRO, Op. cit., p. 83.

46 RODRIGUES, A. Rosa, Op. cit., p. 12

47 Idem, Ibidem, p. 05

48 Idem, Ibidem, p. 05 
nove filhos, e não pensava em parar, o pai dizia: 'que muié era pra parir i home pra criar' e assim foi até a aurora do século" 49 , quando a febre da borracha levou a família Rodrigues para a região de Conceição do Araguaia, cidade no Sul do estado do Pará. Contudo, quando no ano de 1914 a crise da borracha se instalou, o "pai de Braulino, com d. Alfonsina e mais os 15 meninos, se mudaram para o castanhal do Itacaiúnas"..$^{\circ}$

No final da década de 1910, contando com aproximadamente vinte e cinco anos de idade, Braulino Rosa já era apanhador de castanha respeitado entre os camaradas por "conseguir coletar mais de um hectolitro do fruto por dia". Segundo a autora, o pai era um homem "muito trabalhador, desde a juventude, e que se orgulhava de nunca ter sido chamado no barracão por qualquer causa" ${ }^{51}$, e complementa narrando como começava o dia do apanhador de castanha:

Nas sezões [febres] do período da safra, dormitava somente até seis horas da manhã e seguia para o meio da mata. Não entrava mais cedo porque seu irmão, o Afonso "descuidou e um bago [ouriço] de castanha caiu na cabeça”. Despreocupado [Afonso], esqueceu que a castanheira desprende o ouriço quando recebe o orvalho da madrugada, e foi achado morto no dia seguinte. [Braulino] entrava com o calor do sol, pois que sol mesmo não se via "no ponto da panha", e começava a lida. Pés na botina, o direito inteiro, o esquerdo rasgado, entrando água, o que não fazia muita diferença, pois seus pés já eram carcomidos de frieira, após 10 anos pisando no charco. Voltava para a palhoça onde se abrigava, mal e mal, das imensas tempestades por volta das três horas da tarde, pois a partir desse horário não divisava mais o ouriço no chão enlameado. ${ }^{2}$

No trecho acima, as chuvas assinalam não apenas o período que naturalmente era propício à coleta, mas a penúria de se viver sob uma luz difusa, ilhado nos igarapés úmidos, quando não fazia diferença estarem calçados ou descalços, abrigados ou ao relento, pois, presos naquele mundo d'água, estavam sempre encharcados. Mas os signos dos grilhões nos quais viviam metidos os apanhadores de castanha surgem na escrita de Rosa Rodrigues também sob outras formas que não somente "o aguaceiro dos meses de dezembro a maio". ${ }^{33}$

Braulino Rosa, narra Rosa Rodrigues, saía cedo de casa e deixava a mulher alimentando o fogo: "difícil de ser mantido, [pois] que as madeiras estavam sempre úmidas". ${ }^{44}$ Não há informações se a esposa, d. Januária, acompanhava o marido até os locais onde seria feita a "panha do dia", mas a autora consigna que

iam junto com ele três de seus irmãos mais novos e os dois filhos mais velhos [...]. Chegavam ainda dia, mas escuro, de volta a casa com os ossos frios [...] meu irmão mais novo foi atacado de asma, conhecida no castanhal com "puxado", meu pai correu no barracão e deram-lhe muitos comprimidos, que ele não consegue lembrar o nome, mas que não salvou o menino. Sobre esta tragédia, o que mais marcou a lembrança de meus pais não foi o pormenor do acontecido com meu irmão, mas a consequência dos comprimidos, "descontrolou a conta no barracão" e nunca mais puderam sair. 55

49 RODRIGUES, A. Rosa, Op. cit., p. 12

50 Idem, Ibidem, p. 12.

51 Idem, Ibidem, p. 12.

52 Idem, Ibidem, p. 36

53 Grifo nosso.

54 RODRIGUES, A. Rosa, Op. cit., p. 12

55 Idem, Ibidem, p. 57. 
Dois aspectos da experiência narrada acima são primordiais em nossa análise. De um lado, a presença de uma família vivendo e trabalhando cotidianamente no interior do castanhal; de outro, as relações entre vida familiar e escravidão por dívida enunciada pela autora. Detenhamo-nos, inicialmente, sob o primeiro aspecto. Como vimos anteriormente na narrativa do piloto-aviador Lysias Augusto Rodrigues, foi consignada a ausência de famílias, no sentido tradicional do termo, nas matas de castanhais. A presença de mulheres foi por ele reduzida às que constituíam a "classe das prostitutas" e sobre crianças não há quase nenhuma informação. Além de Ana Rosa Rodrigues e de Ignácio Baptista de Moura, um dos poucos a destacar a presença de crianças naquela região é Paternostro que, em 1935, narra:

Deixamos Joana Peres [povoado situado no Vale do Tocantins], depois dum carregamento de 38 hectolitros de castanha. Entre os carregadores vimos duas crianças de 08 anos de idade, que receberam 500 réis pelo trabalho de duas horas. ${ }^{56}$

Diferentemente do relato daquele piloto-aviador, o de Paternostro evidencia a presença de famílias não apenas morando nas proximidades dos castanhais, mas trabalhando também no seu interior. Mas é no relato de Rosa Rodrigues que esse aspecto da vida no castanhal aparece com clareza: os filhos e irmãos de Braulino Rosa habitavam o castanhal durante a safra, embora não somente nessa época. Quanto à esposa deste apanhador, ela certamente residia com os filhos nas pontas e, embora não possamos afirmar com certeza, não é improvável que eventualmente trabalhasse na coleta de castanhas.

$\mathrm{Na}$ verdade, o comerciante de borracha Almeida relata que, em 1912, algumas famílias, sofrendo os primeiros efeitos da crise da borracha, se mudavam para os castanhais, onde "mães, pais e filhos trabalhavam até dez horas por dia para completar a cota exigida pelo patrão". ${ }^{57}$ Paternostro não relata, especificamente, nenhuma experiência com mulheres apanhadoras de castanha, mas ao narrar alguns aspectos do cotidiano no castanhal diz:

O apanhador de castanhas atravessa riachos a pé, ou, de canoa, quando mais profundos. Acompanha picadas, penetra nas matas quase desprotegido, descalço, busto descoberto, chapéu de carnaúba e calça curta. Muitas vezes seguem-no a mulher e os filhos, que o auxiliam na faina..$^{58}$

Das narrativas acima, é possível apreender que famílias compostas de esposas e filhos não eram tão incomuns no cotidiano de trabalho no castanhal. De fato, o outro aspecto que nos referimos acima, a escravidão por dívida, está diretamente vinculado à experiência familiar no interior das matas. Rosa Rodrigues e Paternostro evidenciam traços dessa realidade, cujos significados são disputados nos relatos sobre o universo castanheiro. Principalmente Rosa Rodrigues expõe como para o apanhador de castanha a presença de seus familiares era um fator sobre o qual pesava uma responsabilidade: miscelânea de afetividade "pelos seus" e resignação diante da necessidade de se submeter ao patrão em muitas e variadas situações. Com efeito, é por essa razão que Rosa Rodrigues conta a história de Braulino Rosa, entremeando aspectos da sensibilidade e da responsabilidade sertaneja:

56 PATERNOSTRO Op. cit., p. 81.

57 ALMEIDA, Op. cit., p. 68.

58 PATERNOSTRO, Op. cit., p. 81. 
Naquele dia, a febre atingiu com muita força o menino. Meizinha [remédios caseiros] não adiantava. Meu pai dizia: "Ver o menino naquele 'sufrimento' não tava aguentando”. Foi ao encarregado do barracão que lhe entregou os remédios e fez as anotações no caderno de conta. Ele voltou aliviado para casa, pensando que a vida do filho estava salva. Mas depois de três dias ele morreu nos braços de minha mãe [...]. Braulino [o pai da autora] olhava de longe, com olhos duros e perdidos de dor, seguro no punho da rede. ${ }^{59}$

O "sofrimento silencioso" de Braulino resulta tanto do amor por seu filho quanto da frustração por não ter conseguido cumprir sua responsabilidade: proteger sua família, um importante valor para o sertanejo do Vale do Tocantins-Araguaia. A responsabilidade de proteger os seus, no caso de Braulino Rosa, está vinculada a uma dimensão da vida sertaneja que, apesar da complexidade das relações familiares, ainda é determinada por um código de honra mais ou menos rígido e que tem entre suas regras a obrigação do pai pelo sustento e proteção dos filhos e da mulher.

Outra dimensão importante é que a própria narrativa de Rosa Rodrigues se constitui em uma forma de resistência que, ao se contrapor às concepções que procuram pensar o apanhador de castanha ora como vítima, ora como "marginal”, busca construir sentidos diferentes para as práticas desses trabalhadores. Percebe-se em sua narrativa uma disputa, de narrativas diferenciadas, de uma memória ambígua, mas que não se quer vitimizada e nem marginalizada e por isso protesta contra os significados da outras narrativas, com as quais trava um combate.

Não alcançar, apesar de todo o esforço, que o filho sobrevivesse, marca Braulino Rosa não apenas no campo afetivo, mas na dimensão da honra sertaneja. Contraíra uma dívida e nela estaria preso até a morte, não exclusivamente em função do controle físico - que a ideia da prisão em um mundo d'água representa muito bem -, mas da subordinação a que estava vinculado culturalmente. De fato, a metáfora do castanhal como uma ilha, cercada de água por todos os lados, representava na narrativa de Rosa Rodrigues tanto o controle do escoamento da produção quanto a dominação e as tentativas de ordenamento social e cultural que os patrões infligiam aos apanhadores de castanha por meio do controle dos recursos e dos meios disponíveis com os quais estes últimos podiam tratar e cuidar de seus familiares. E era assim que ela protestava em sua narrativa: que fosse assim narrada, assim compreendida.

Esse controle não poucas vezes era exercido socialmente com o reconhecimento das regras da subordinação por parte do apanhador de castanha, quando, por exemplo, negava-se a fugir à palavra empenhada ou a não reconhecer um débito, mesmo quando exorbitantemente aumentado. Sobretudo, a legitimidade da dominação exercida e reconhecida como parte do cotidiano dos apanhadores de castanha é um campo da hegemonia cultural construída e partilhada nesse sertão, não apenas pelos apanhadores de castanha, mas também por muitos grupos sertanejos que de uma forma ou de outra constituíram uma rede de valores sociais que sancionava o controle hegemônico dos grupos dominantes sobre as classes trabalhadoras.

Esse é o caso de Rosa Rodrigues, que mesmo filha de Braulino Rosa, um apanhador de castanha, está presa a essa legitimidade. De suas próprias lembranças acerca do pai, Rodrigues afirma:

59 RODRIGUES, A. Rosa, Op. cit., p. 58 
Meu pai, me lembro bem, era um homem cordato, de poucas palavras, quase calado. Resignado, conhecia seu lugar, mas era um homem de palavra, cumpria o que prometia. Orgulho nele, só de não faltar compromisso. De sua vida, ainda agora na velhice, o que tem de mais forte é o reconhecimento de que foi seu patrão que lhe permitiu criar meus irmãos. ${ }^{60}$

A compreensão de Rosa Rodrigues sobre o caráter de seu pai é representativo da legitimidade que os valores da classe dominante alcançam entre os sertanejos quando se trata das relações de trabalho. Corroborando essa visão de um sertanejo "passivo" e "resignado", o frei dominicano José Maria Audrin escreveu em 1947:

O sertanejo está destinado, pela sorte, a viver longe dos meios chamados civilizados, privado de muitas vantagens de que gozam os habitantes das zonas adiantadas. De tudo quanto lhe foi recusado pelo destino, recebe, de vez em quando, informações detalhadas, talvez exageradas, que não deixam de fazê-lo sonhar. E, todavia não se lamenta, nem é atormentado pela inveja. Suporta, de bom grado, as dificuldades e privações [...] e chega a gostar da solidão e aspereza de sua existência. ${ }^{61}$

A "resignação imperturbável" que Audrin explicou ter sido forjada por "profundas convicções religiosas" e ser uma característica geral dos sertanejos que habitavam, nas primeiras décadas do século XX, os vales dos rios Araguaia-Tocantins, foi descrita por Rosa Rodrigues como um traço particular do caráter de seu pai, cuja origem parecem ser as tradições e os valores sociais do sertão dos vales. Não cabe nos limites deste artigo problematizarmos as aproximações e os distanciamentos entre as dimensões religiosas e costumeiras dessa "resignação" na construção da dominação e da legitimação da escravização por dívida, porém, para além da tradição cultural ou religiosa, parece-nos pertinente afirmar que, diante das experiências partilhadas no interior dos castanhais, os trabalhadores faziam suas escolhas de acordo com as condições e com as possibilidades que poderiam ser vislumbradas em seus horizontes.

Por outras palavras, não é improvável que Braulino Rosa, antes de assumir a dívida "resignadamente", tenha avaliado suas reais condições de manter a família e de "escapar" das consequências físicas, escolhendo, ao final, permanecer no castanhal. Não se trata apenas de submissão, trata-se de ser capaz de entender os caminhos da negociação e da resistência em meio aos espaços da dominação por meio da adequação a determinadas situações que, como experienciavam os apanhadores de castanha, poderiam ser transitórias e culminarem, ao menos potencialmente, em novas negociações e/ou resistências futuras. No caso dos apanhadores de castanha, os caminhos da resistência e da negociação eram uma opção pouco segura e, em função das sutilezas presentes em sua constituição, dificilmente identificáveis nas evidências deixadas para a posteridade.

Em se tratando, especificamente, das práticas de resistência desses trabaIhadores, podemos demarcar com segurança, como apresentado na primeira parte deste artigo, que as tentativas de fuga foram uma das estratégias que expressavam a potencialidades dos trabalhadores para resistir à exploração. Com efeito, em muitos dos relatórios de funcionários públicos que passaram pela região dos castanhais, tenham sido eles militares ou civis, há referências ao fato de que o apanhador de castanha vivia permanentemente vigiado. Além disso, na maioria

60 RODRIGUES, A. Rosa. Idem, Ibidem, p. 18.

61 AUDRIN, José Maria. Sertanejos que eu conheci. Rio de Janeiro: José Olympio, 1963, p. 118. 
dessas referências, essa prática é explicada como parte do arsenal de controle dos patrões, cujo fito seria impedir aqueles trabalhadores de fugirem ou de descansarem de suas fadigas cotidianas.

Entretanto, Paternostro apresenta, durante sua passagem pelo castanhal de Joana Peres, alguns elementos que nos encaminham para outras possibilidades de resistência que não apenas a fuga ao cativeiro. Esse médico, ao narrar suas impressões acerca da indústria da castanha, afirma, como vimos acima, que os patrões impediam seus apanhadores de saírem das matas, o que, inicialmente, parece ser apenas uma estratégia de controle dos trabalhadores. Mas o que escreve algumas linhas abaixo ilumina outra perspectiva:

\begin{abstract}
Os aviadores e arrendatários (nome que se dá aos comerciantes do Baixo Tocantins) utilizaram-se dos meios de transporte modernos para isolar, na mata, os apanhadores de castanha, extinguiram a especulação da época dos barcos a remo, nos quais os párias transportavam os produtos silvestres para vendê-los nas vilas. [Hoje] nos "portos" das áreas exploradas o preço da castanha e das mercadorias é compulsório. ${ }^{62}$
\end{abstract}

É necessário aqui buscar ler nos silêncios de Paternostro as práticas dos apanhadores. Quando esse médico expõe que os trabalhadores da castanha têm sua mobilidade restrita pelos patrões, não está, exclusivamente, apontando para a questão da escravização por dívida, mas enunciando uma estratégia para controlar o produto do trabalho do apanhador que, dentro de suas possibilidades, procurava levar suas castanhas para a vila e negociar longe dos olhos e dos preços compulsórios de seus patrões. Nesse sentido, os barcos a vapor significaram um braço forte ao patrão que, indo buscar a produção nas pontas dos castanhais, impedia que os trabalhadores levassem as castanhas coletadas para a cidade de Marabá em "suas pequenas embarcações". A questão era o controle da produção de castanhas.

Nessas situações, o apanhador de castanha era ilhado nos centros da mata e mantido isolado até o fim da safra. O isolamento era garantido pela presença de um vigia que era pago pelo "dono do castanhal" para combater os ataques de índios e, principalmente, para impedir que os trabalhadores se dirigissem às vilas e conseguissem comercializar sua safra por um preço melhor do que aquele pago pelo "patrão". No relato de Rosa Rodrigues, encontramos uma referência a essa prática, quando diz:

Dentro do calado [silêncio] de Braulino Rosa, estava não apenas a tristeza pela morte do filho, mas o desgosto pelo que ele considerava "a vergonha maior da família": o irmão de d. Afonsina [esposa de Braulino Rosa e mãe da autora] que, depois de tirar do castanhal o que não lhe pertencia durante anos, foi "pego no pulo" pelo vigia. Levou uma surra pra não esquecer, e apesar de tudo, depois fugiu, tinha suas reservas e parece que ficou rico. Não se sabe, meu pai [Braulino Rosa] não diz seu nome e nós, concordando com ele, esquecemos do tio, também morreu. ${ }^{63}$

Não é possível saber mais acerca do cunhado de Braulino Rosa e nem mesmo Rosa Rodrigues esclarece. Contudo, considerando-o um acontecimento e sujeito representativo de uma prática que parece não ter sido única, podemos fazer algumas inferências. Em primeiro lugar, evidencia-se um "jogo de valores" que, cons-

62 PATERNOSTRO, Op. cit., p. 81

63 RODRIGUES, A. Rosa, Op. cit., p. 64 
truindo um amálgama entre honestidade e lealdade, busca estabelecer uma rede de submissão às regras sociais do capitalismo.

Com efeito, a forma como Rosa Rodrigues encerra o capítulo que trata da personalidade de Braulino, afirmando que seu tio, assim como seu irmão, também estaria morto, reapresenta o espaço em que, no cotidiano dos apanhadores de castanha, a exploração capitalista construía sua versão cultural: os valores sertanejos. O irmão de Rosa Rodrigues morrera de uma febre, ou seja, de morte natural; seu tio não morrera de fato, mas estava morto socialmente para Braulino Rosa, para a autora e, possivelmente, para a cultura e para a sociedade castanheira, por ter transgredido a ordem social estabelecida no sertão em meio às negociações e às adequações dos trabalhadores.

Em segundo lugar, a própria autora relata que seu tio, “apesar de tudo, depois fugiu, tinha suas reservas e parece que ficou rico". As informações são apenas essas, mas a expressão "apesar de tudo" pode significar não apenas a "vergonha", mas também uma saída, uma possibilidade de transgressão e de luta contra a exploração. Isso não é improvável, pois Moura é um dos que registra o fato de a castanha-do-pará ter se tornado um produto de exportação, ou seja, controlado pelo grande capital inglês, desde a primeira década do século XX. ${ }^{64}$

O engenheiro Américo Barbosa de Oliveira é outro que afirma existir entre o apanhador de castanha e as casas exportadoras de Belém diversos extratos de atravessadores que vão dos donos dos castanhais aos patrões. ${ }^{65}$ De fato, não é inviável pensar que os atravessadores que esperavam em Marabá por oportunidades de conseguir um carregamento livre dos preços praticados pelos "donos dos castanhais" viam uma possibilidade de lucro nas estratégias dos apanhadores para "subtrair" as castanhas.

Por último, é importante observar que, se de um lado, dentre as práticas de controle dos trabalhadores, estava a ressignificação da própria cultura sertaneja, buscando redefinir um imaginário social que legitimasse a exploração; de outro, os apanhadores de castanha, assim como outras categorias de trabalhadores dos vales do Araguaia-Tocantins, também buscavam manipular os mecanismos do capital que, historicamente, têm na competitividade um de seus principais aspectos. Diante disso, conscientemente ou não, os apanhadores, ao negociarem sua produção com os concorrentes de seus patrões, estavam de certa forma mobilizando suas estratégias de sobrevivência para desestruturar os mecanismos de exploração que lhes eram impostos.

\section{Conclusão}

Esse mundo d'água e de exploração realizava-se no universo do apanhador de castanha, estabelecendo os limites de sua movimentação física, construindo fronteiras simbólicas que favoreciam a exploração e a dominação, ao colocarem no centro inundado dos castanhais as famílias daqueles trabalhadores. De fato, a organização do trabalho nos castanhais em moldes capitalistas demandava uma articulação entre determinada "resignação à exploração" e uma moralização do trabalhador. Nesse jogo, valores como honestidade e empenho da palavra eram

64 MOURA, Op. cit., p. 153.

65 OLIVEIRA, Américo L. B. Considerações sobre a exploração da castanha no baixo e médio Tocantins. In: Revista Brasileira de Geografia. n.01, v. II, 1941. 
transfigurados, dentro do discurso que dividia o mundo sertanejo do mundo civilizado, em submissão e conformismo.

Ademais, problematizando as narrativas, percebemos que nas relações de força entre patrões e trabalhadores as possibilidades dos últimos de resistirem à exploração diminuíram com a chegada "dos meios de transporte modernos" e essa parece ter sido uma tendência geral nos vales dos rios Araguaia-Tocantins: relações de trabalho arcaicas vis a vis com modernização tecnológica. Os esforços dos patrões dirigiam-se ao controle, não apenas do trabalhador, mas também e principalmente contra as formas de resistência ao domínio do capital, que se infiltrava nos nervos centrais da produção da castanha por meio e a partir do controle do cotidiano dos castanheiros.

Por outro lado, os trabalhadores dos castanhais aprenderam, desde antes da chegada do trabalho livre, que era necessário reelaborar constantemente o conjunto de práticas que constituíam suas experiências conforme seus interesses e necessidades. Mas não foi somente esse o seu aprendizado, a pedagogia dos patrões, que utilizava inclusive os próprios valores sertanejos, foi algumas vezes colocada às avessas, quando os apanhadores utilizavam, por exemplo, a "livre concorrência” entre os diversos comerciantes de castanha que circulavam por Marabá como aliada em sua luta para minimizar a exploração que sofriam.

Finalmente, compreender esses campos de atuação e de luta contra a exploração somente é possível quando ultrapassamos a leitura simples e direta das fontes reconhecidamente oficiais. Além disso, devemos colocar em perspectiva, especialmente quando se trata da história do trabalho e dos trabalhadores, a necessidade de investigar materiais qualitativamente diferentes daqueles que, tradicionalmente, estamos acostumados a analisar.

Do ponto de vista dos processos, as grandes sínteses não perderam sua importância dentro do universo das reconstruções históricas. Contudo, é necessário buscar outros horizontes, a exemplo dos estudos regionais que têm conseguido apontar outras possibilidades interpretativas das realidades dos trabalhadores. Possibilidades essas capazes de iluminar a compreensão, não apenas das resistências e adequações dos grupos subalternos, mas de apontar caminhos de interpretação das formas pelas quais os grupos dominantes, a serviço do capitalismo, são capazes de se refazer diante dos cenários mais complexos da contemporaneidade.

Recebido em 07/12/2012

Aprovado em 21/04/2013 